\title{
Le projet A.P.A.D. et le projet du peuple
}

\section{Michael Singleton}

\section{(2) OpenEdition}

Journals

Édition électronique

URL : https://journals.openedition.org/apad/350

DOI : 10.4000/apad.350

ISSN : 1950-6929

\section{Éditeur}

LIT Verlag

\section{Édition imprimée}

Date de publication : 15 décembre 1991

\section{Référence électronique}

Michael Singleton, « Le projet A.P.A.D. et le projet du peuple », Bulletin de l'APAD [En ligne], 2 | 1991, mis en ligne le 28 juin 2006, consulté le 21 septembre 2021. URL : http://journals.openedition.org/apad/ 350 ; DOI : https://doi.org/10.4000/apad.350

Ce document a été généré automatiquement le 21 septembre 2021.

Bulletin de I'APAD 


\title{
Le projet A.P.A.D. et le projet du peuple
}

\author{
Michael Singleton
}

1 Fils à papa ou fils du peuple, quel est l'anthropologue qui n'a pas une tête de prophète et un cœur de populiste? Enfant terrible, vaticinant contre les valeurs et les visions de son milieu d'origine, l'ethnologue européen s'est souvent fait le protecteur et le promoteur de son peuple choisi; enfant du terroir, l'anthropologue africain se voit mandaté par les siens pour les authentifier tout en améliorant le triste sort qui leur est fait. Il se peut qu'il y ait des anthropologues qui ne s'imaginent pas ainsi, mais il serait difficile de nier que c'est ainsi que l'espèce est fichée dans l'Imaginaire occidental. D'ailleurs, à moins d'être un Turnbull ou un Barley, comment ne pas faire cause commune avec son peuple quand, d'une manière manifeste, il vous a, en règle générale, si bien accueilli et quand, d'une façon latente, il fait non seulement vivre son anthropologue attitré jusqu'à la fin de ses jours, mais peut, le cas échéant, en fin de carrière, promouvoir l'un des membre de l'Académie et parachever l'autre comme "Sir" ? ${ }^{1}$

Qu'il se réclame haut et fort du Peuple ou qu'il se sente simplement redevable à lui, l'anthropologue parait condamné par devoir d'Etat à se (pré)occuper du Peuple. L'anthropos" dont l'anthropologie cherche à décoder la logique serait primordialement l'Homme du Peuple. De l'anthropologie sociale à l'anthropologie socialiste le sentier est-il plus étroit que le chemin qui mène du culturalisme au capitalisme ? ${ }^{2}$ C'est là une question de déontologie et pas de démagogie. Et l'APAD,-qui est à la recherche d'une problématique propre et porteuse pour mettre son pignon sur la rue, déjà surpeuplée, du développement africain, pourrait-elle mieux faire que de se (con)centrer sur un thème "populaire" ?

3 Mais en parlant du Peuple, en voulant partir de ou avec Lui, on n'a encore rien dit si ce n'est d'ordre heuristique. De quelle réalité sociologique s'agit-il ? Clarifier une optique, déclarer une option ne sont que des démarches préliminaires, indispensables, certes, mais néanmoins "purement" instrumentales. De quel Peuple s'agit-il ? Attention à la (con)fusion entre grilles d'analyse et gens concrets. 
Christophe Colomb n'a pas trouvé l'Amérique, il l'a inventé. Ce qui ne veut pas dire qu'il l'a créé de toutes pièces, mais qu'il a bricolé, à partir de ses impressions, sensiblement autre chose que l'Amérique que les indigènes s'étaient déjà donnée. De même, les idées que l'anthropologue se fait des modes de production et de reproduction humains ne sont pas de simples reflets plus ou moins subjectifs de réalités objectivement existantes. Entre les données de terrain et ce qu'elles nous donnent à penser intervient le travail créateur de nos esprits respectifs. S'il est vrai que "qui cherche trouve", l'explorateur qui finit par tomber sur la rivière qu'il cherchait, le fait "mentalement". Car, épistémologiquement, la matérialité de l'eau en question ne peut être au sens le plus littéral de l'expression anglaise un after tought. Donc, il ne peut pas plus être question de rencontrer le Peuple en tant qu'objet de notre projet que de s'achopper contre des fétiches ou des formes de la famille. Le Peuple n'est pas déjà là, dans toute sa splendeur substantielle et significative, simplement en attente de sa découverte par un anthropologue de passage dans les parages. Nous devons décider de son existence en fonction des données phénoménologiques comme nous le faisons pour n'importe quelle autre de nos constructions anthropologiques. Le tout c'est que nos productions soient plausibles, que nos créations soient crédibles.

5 Or, sur le terrain, comment ne pas être frappé par le phénomène primordial de l'inégalité quand même un philosophe en chambre s'est vu obligé de conclure à l'opposition entre le Maître et l'Esclave comme primum movens du social-historique ? Donc, à un niveau d'abstraction "très élevé", le Peuple est fait de tous ceux qui se trouvent en position subalterne. D'un côté les dominants, de l'autre les dominés.

6 Mais deux remarques s'imposent immédiatement si on veut éviter des téléscopages indus et des remplissages définitifs de cette première grille. D'un côté, bien que toute relation. humaine soit un rapport de force inéluctablement asymétrique, elle ne se réduit pas, même en dernière analyse, à une exploitation aliénante. Avant qu'un Peuple se doive de s'affranchir par un recours à la violence révolutionnaire, il y a trente-six solutions imaginables et possibles qu'il peut légitimement envisager : négociation, réforme, compromis, complicité, retraite voilà quelques unes des stratégies grâce auxquelles un Peuple peut trouver que ses comptes, en attendant, sont justes - et cette attente peut durer des siècles. De l'autre, on n'est jamais définitivement partout et toujours du Peuple. Esclaves face à leurs patrons, les "prolétaires" du Nord font désormais figure de Maîtres par rapport aux Damnés des Terres méridionales. Mais les élites compradores sont là pour nous rappeler qu'il ne suffit pas d'avoir la peau noire pour jouir d'un mandat populaire. Et toutes les viragos de l'histoire - anglo-saxonne du moins - sont là aussi, de Boadicée à Mme Thatcher en passant par la reine Elizabeth I, pour suggérer que l'envie d'une protubérance phallique peut mener plus loin que la simple émancipation féminine.

7 N'est donc pas toujours du Peuple celui qui le croit. A la limite, d'ailleurs, personne ne peut se dire clairement et consciemment du Peuple, puisque par définition les jeux du langage populaire relèvent de l'ordre "ordinaire" - du common sense des philosophes anglais ou du sens pratique d'un Bourdieu. Mais, au dedans de cette limite, c'est l'anthropologue qui est le mieux placé pour voir qui a été et qui est encore du Peuple. (On voit ainsi que la problématique du Peuple se trouve à un carrefour interdisciplinaire - de l'histoire, de la sociologie, de la philosophie raison de plus pour qu'il soit pris en considération par une association qui se veut transdisciplinaire.) 
Une distinction pourrait nous aider à mieux aborder et articuler notre problématique. Prenant le concept de culture dans son acception la plus holistico-systémique, il est possible de parler des "Choix de Société Globaux" comme constituant autant de Projets - de Visions du et de Visées sur le monde. ${ }^{3}$ Chaque Projet secrète une pléthore de méso-projets qui à leur tour donnent lieu à une myriade de micro-projets. Tous ces projets (sans majuscule) reprennent et activent le Paradigme d'Ensemble de la même façon que nos cellules nous (re)produisent : tout en contenant le programme en entier, chaque cellule se charge de la réalisation de la partie qui lui convient.

9 De nouveau cette distinction est foncièrement heuristique. Elle vaut à plusieurs niveaux d'analyse. D'un point de vue macro, l'Occident lui-même constitue un Projet que certains, d'ailleurs, dont moi-même, ${ }^{4}$ estiment synonyme de Développement. Mais un club d'entomologistes parisiens fonctionne aussi comme un Projet. Tout Projet se divise en plusieurs sous-systèmes: ainsi le Projet Occidental se reconnaît dans les sphères du religieux, de la politique, du "culturel", de l'éducation, de la santé etc. A son tour chaque secteur connaît des réalisations plus concrètes: en Occident, il y a des églises et des sectes, il y a des partis politiques, il y a des écoles privés et des écoles publiques, il y a la bio-médecine et des médecines parallèles.

Tant qu'on tourne en rond au-dedans d'un même Projet (ou Paradigme), tant que les parties s'articulent au même Tout, les dégâts sont limités puisqu'il ne peut s'agir que de querelles de clochers aux sons de cloches de longueur d'onde, plus ou moins différente. Des malentendus autrement plus profonds surgissent quand un Projet part à l'assaut ou à l'aide d'un Autre - quand, par exemple, l'Europe se porte au secours de l'Afrique. Car il n'est pas dit, loin de là, que le Projet dit "partenaire", mais en réalité subalterne, fonctionne selon les découpages en cours dans le Projet hégémonique. Ainsi des chrétiens européens, s'ils ne partent plus en croisade contre les musulmans, s'engagent dans un dialogue avec un Islam qui ignore la division entre l'Église et l'État; ainsi des médecins occidentaux (ou occidentalisés) voudraient soigner une Afrique qui a été "programmée" pour exiger de son personnel soignant non seulement des soins corporels, mais même, sinon surtout, la pluie et le beau temps ainsi que la remise en ordre des affaires communautaires. On offre la science là où il y a une demande de sorcellerie. ${ }^{5}$

11 Nous avons illustré notre grille par un exemple inter-culturel, mais elle vaut aussi intra-culturellement. En fait chaque culture et même sous-culture constitue un Projet avec ses projets attenants. La France fait face à l'Angleterre...et vice versa. Au cœur de l'Hexagone, Paris est confronté à la France profonde. Dans le moindre village, dans la plus insignifiante des associations, il y a d'un côté les autorités qui ont apparemment le pouvoir et de l'autre les gens qui tout aussi manifestement le subissent.

"Jusqu'ici" me dira-t-on, "rien que des lieux communs fréquentés synchroniquement par un Bourdieu ou un Balandier et des sentiers battus diachroniquement par un Ariès ou un Ranger." Mais, justement, l'A.P.A.D. ne pourrait-il pas faire pour le développement ce que ces chefs de file ont fait les uns pour l'invention du quotidien en Europe, les autres pour l'inventaire de la religiosité populaire en Afrique?

On a dit trente-six choses sur le développement en général et le développement africain en particulier : les uns l'appellent béatement comme une panacée à l'afro-pessimisme régnant, les autres l'exècrent comme le dernier avatar sournois de l'impérialisme occidental, tandis que la plupart se résignent à le voir arriver comme un mal nécessaire. Mais ceux, indigènes ou expatriés, qui ont dit toutes ces choses ont 
rarement été du Peuple. Ne serait-il pas opportun de voir comment le développement (dans tous ses états) a été perçu, vécu et reçu par les différents Peuples au cœur des populations africaines? Que disent-ils de vive voix du développement, mais surtout que font-ils (in)consciemment pour ou contre lui ? Combien veulent le développement tel qu'il est ? Combien diraient "oui" à des développements alternatifs ? Combien, par tout ce qu'ils font, disent en fait "non" au développement? Le Peuple a-t-il élaboré d'autres projets de développement, peut-il avoir un autre Projet que le Développement en tête ?

Donnez non pas la parole au Peuple - un langage commun au Maître et à l'Esclave peut-il être moins factice que l'esperanto ? - mais lui laisser sa parole, quoi de plus indiqué pour un prochain colloque d'une association euro-africaine d'anthropologues sociaux et d'africanistes sociables?

\section{NOTES}

1.Ce fut le cas de feu mon maître Sir Edward Evans-Pritchard- lui qui, avec son sourire de "gentleman-trickster", me disait à l'époque où il était question que l'héritier du trône d'Angleterre fasse de l'anthropologie : "ce serait le comble qu'on le confie à un spécialiste des sociétés acéphales !" En fait, n'étant pas de niveau "post-graduate", on aiguillera le prince vers l'autre université, Cambridge, où il y avait des gens qui s'y connaissaient en cultures plus aristocratiques.

2.Est-ce un pur hasard? mais c'est un fait que les premiers à subir la crise d'identité provoquée par la collusion (in)consciente entre Anthropologie et Impérialisme furent nos collègues américains, cultural anthropologists par définition.

3.Cf "Projet et projets", Cahiers du CIDEP, n 7, 1990 (Université Catholique de Louvain, Belgique) .

4.Mais surtout S. Latouche, Faut-il refuser le développement ?, Paris, PUF, 1986 -, qu'on ne saurait trop recommander à des anthropologues actifs et/ou activistes. (Voir la rubrique "Lu et à Lire").

5.Dans un Cahier du CIDEP : "Soins de santé primaire - cause perdue ?" (sous presse), j'essaie de montrer (avec beaucoup de succès à mon avis) toute l'équivoque ethnocentrique qu'il peut y avoir à parler de "la médecine traditionnelle africaine" dans la mesure : 1) où il n'y a pas une mais plusieurs Afriques ; 2) où "traditionnel", à l'instar d'autres termes comme "tropical" ou . désertification", est un euphémisme pour "misère" et "marginalité" ; 3) où le nganga, réduit plutôt que traduit par "guérisseur", fut tout autre chose qu'un simple médecin qui s'ignorait. 


\section{AUTEUR}

MICHAEL SINGLETON

CIDEP, Louvain 